\title{
Exploring the Impact of Supplier Development Practices on Manufacturing Responsiveness in Malaysia
}

\section{Rahayu Tukimin ${ }^{1,3^{*}}$, Wan Hasrulnizzam Wan Mahmood $^{2}$, Mohd Razali Muhamad $^{1}$, Maimunah Mohd Nordin ${ }^{3}$}

\author{
${ }^{1}$ Faculty of Manufacturing Engineering, \\ Universiti Teknikal Malaysia Melaka, Hang Tuah Jaya, 76100 Melaka, MALAYSIA \\ ${ }^{2}$ Faculty of Mechanical and Manufacturing Engineering Technology, \\ Universiti Teknikal Malaysia Melaka, Kampus Teknologi, Hang Tuah Jaya, 76100 Melaka, MALAYSIA \\ ${ }^{3}$ Kolej Kemahiran Tinggi Mara Kuantan, KM. 8, Jalan Gambang, 25150 Kuantan, Pahang, MALAYSIA \\ *Corresponding Author
}

DOI: https://doi.org/10.30880/ijie.2020.12.05.020

Received 30 January 2020; Accepted 2 June 2020; Available online 30 June 2020

\begin{abstract}
Responsiveness in manufacturing is now a key to a competitive edge in an advanced manufacturing environment. The mutual relationship with a supplier is important in formulating the responsive supply chain. Therefore, this study is carried out to discover the extent of supplier development (SD) practices in influencing the manufacturing responsiveness (MR) to the manufacturing firms particularly in Malaysia. Data was collected from 71 manufacturing firms that accredited ISO 14001 via survey questionnaires. The results reveal that the development of suppliers has a positive and meaningful impact on MR. However, not all SD practices correlate equally to the MR practices. This finding can be used as a guideline for the manufacturing industry, mainly in Malaysia to understand better and deeper valuable information on the impact of SD practices towards manufacturing responsiveness as well as strengthening the SD practices to further enhance a responsiveness level in manufacturing.
\end{abstract}

Keywords: Manufacturing Responsiveness, Supplier Development, Manufacturing Firms, EMS-ISO 14001, Malaysia

\section{Introduction}

In the era of a global manufacturing environment, the success of manufacturing firms is always associated with the ability to adapt to the dynamic changes in customer needs and requirements. In this case, manufacturing firms should have the capability of offering a variety of innovative and customised products according to customer specifications and taste [1]. The response rate to the customer needs could be improved by enhancing the manufacturer's capability; for example in terms of delivery speed and flexibility of the product and process. There are many causes of delayed delivery, including facility disruption that occurred at production and facility centres. The recovery time of the disrupted facilities must be as minimal as possible to make sure everything is back to normal in the shortest time [2]. In developing these capabilities, collaboration and integration with suppliers seem to be one of the ways by setting up goals and objectives between manufacturers and suppliers. These provide a clearer picture of future strategic direction, as well as smooth and strengthen the production operations.

In Malaysia, the manufacturing firms make a substantial contribution to the Malaysian economy and accounted for $81.5 \%$ of Malaysia's total export in 2016. The situation also occurred in Singapore where electronics industry in 
Singapore since 2012 is the strength of the manufacturing sector by contributing $5.2 \%$ to the gross domestic product.[3]. For these reasons, manufacturing firms must always increase their initiatives in raising their productivity. In this case, the role of suppliers is vital. Manufacturing firms and suppliers are interdependent on each other particularly in increasing their quality, flexibility, and profit [4].

In sustaining their operations, manufacturing firms have begun to focus on SD programmes. The practices available for the SD programme are extensive and it is reasonable to assume that not all manufacturing firms can afford to incorporate all these practices. The implementation of the SD programme requires a manufacturing firm to allocate their time and resources to their investment. A good relationship and collaboration between manufacturing firms and their suppliers can impact the overall success of a firm's ability to offer quality products and services [5]. In the absence of such a relationship, manufacturing firms are not able to meet customer required changes and thus lack its needed responsiveness. Thus, to keep maintaining the performance of suppliers, supplier development programme is one of the tools to improve supplier capability and performance. Therefore, this paper analysed the impact of supplier development towards manufacturing responsiveness.

\section{Literature Review}

\subsection{Supplier Development Practices}

Supplier development (SD) was a collaboration activity between manufacturing firms and their suppliers focusing on improving buyer-supplier relationship and supply chain performance. It can be any set of activities typically initiated by the buying firm purposely in identifying, measuring and improving supplier performance as well as facilitate the continuous improvement of the overall goods and services supplied to the buying firm. Previous literature has shown that the implementation of the SD programme gives a significant contribution to improve product quality, reduce cost, shorter lead times and higher supplier flexibility [4-5]. The motivation and efforts of suppliers to participate in the SD programme enabled them to enrich their competencies and capabilities.

Traditionally, supplier development focussed on economic goals and sought to develop suppliers' economic performance and capabilities related to the quality, cost, and delivery. However, due to the globalisation in business, competitive market situations and the changing customers' demands, a number of criteria included economic, social and environmental aspects should be addressed during selecting the suppliers to be developed [8]. The environmental aspect is important to extend the product life-cycle as well as helping in lessening environmental risks and increase the competitiveness of the organisation. SD practices include cooperation and communication [9]; investment, knowledge transfer and resource transfer [10]; and performance assessment through formal evaluation, monitoring and auditing [11]. In this study, the scope of SD has been broadened from developing supplier capabilities to increase the level of supplier willingness, in order to meet the buying firm's short and long-term supply needs so that manufacturing responsiveness can be enhanced.

\subsection{Manufacturing Responsiveness}

The importance of responsiveness has been widely discussed in the academic literature as it is a key to a competitive factor in today's business environment. The level of responsiveness is always associated with the period of time where the final product reaches the target customer. Generally, a responsive organisation is able to respond to the customers' short-term demand changes. It is important for any organisation to provide the right product, at the right quality and price within the minimal lead time.

The concept of responsiveness has a number of different meanings described within manufacturing literature. However, the level of responsiveness is different between the firm and it is depending on firms' individual business strategies [12]. Gindy et al., [13] describe manufacturing responsiveness as the ability of the manufacturing system to respond rapidly towards predictable and unpredictable demands in a manufacturing environment. Zuhriah et al., [14] present the manufacturing responsiveness based on input/output system in the manufacturing operations where responsiveness driver as an input, responsiveness enablers and measures as a process, and responsiveness impact as an output. It is also believed as the capability to please wide-ranging and repeatedly changing customer needs after the preliminary entry of their order [15].

Responsiveness also depends on the requirement of timely and accurate information distribution regarding customer demand patterns and changing needs among supply chain partners. The use of information and communication technology, particularly the internet of things (IoT) where it is the integration of several technologies seems to be an effective way to ensure the information flow across the supply chain smooth and transparent [16]. However, in meeting customer requirements, manufacturing firms should carefully manage the production resources so that no excessive costs, time, organisational disruptions, or performance losses. In order to meet the customer change requirement, it can't be denied that the role of the supplier is important. 


\section{Research Method}

To collect the data, a questionnaire-based survey consisting of 36 SD-related items and 17 MR-related items was circulated to 264 manufacturing firms that accredited with EMS ISO-14001 in Malaysia. The list of those manufacturing firms was obtained from the Standards and Industrial Research Institute of Malaysia (SIRIM) database. The rationale for selecting EMS ISO-14001 accredited manufacturing companies is based on the justification that they are expected practicing green activities. Respondents with a minimum of 2 years of experiences from each firm are required to rate the perception of performance using five Likert-scale anchored at " 1 - poor", " 2 - fair", " 3 - good", " 4 - very good" and "5 - excellent". In addition, scale zero is included in indicating the item questioned was not practiced by respondents. Self-addressed, stamped returned envelope is enclosed as an initiative to increase the response rate. Initially, the returned questionnaires were received from 78 manufacturing firms. However, 7 were set aside ( 2 due to incomplete information, 5 due to non-target group respondents), representing a $29.55 \%$ response rate.

A statistical software analysis package IBM SPSS version 22 was applied in performing the data analysis. Questionnaire responses were codified and inserted into the database. Descriptive and inferential analysis techniques were suggested for investigating the objective of this study. Reliability analysis is performed to check the consistency of the measures used. Meanwhile, the Spearman correlation test was used in order to investigate the relationship between SD practices and MR performance.

\section{Results and Discussion}

\subsection{Demographic Information}

The demographic data illustrates that the greatest percentage of respondents are from the Asian company ownership (47.89\%) followed by Malaysian company ownership (30.99\%) and the US and European company ownership (21.13\%). In terms of the industry product group, $47.89 \%$ is from electrical and electronics, followed by $15.49 \%$ from automotive, $11.27 \%$ from mechanical, and $2.82 \%$ from the chemical and scientific product group. The remaining $22.54 \%$ is from others such as pharmaceutical, food and beverages, and paper products. The data shows that $59.15 \%$ of the manufacturing firms operate with the employee capacity between 150 to 750 employees, followed by $21.13 \%$ with less than 150 employees and $19.72 \%$ with more than 750 employees. Approximately, half of the manufacturing firms $(53.52 \%)$ had obtained ISO 14001 certification for more than 10 years. In the context of respondent background, $1.41 \%$ holding a position as CEO/director, manager/assistant manager (32.39\%), senior engineer/engineer $(32.39 \%)$ and executive $(33.80 \%)$ with more than 2 years of working experiences at the current positions.

\subsection{Reliability Analysis}

Reliability analysis is conducted in this study to check the consistency of the measures used and measured using Cronbach's alpha coefficients. The measures are considered to have a sufficient level when the Cronbach's alpha value is equal to or greater than 0.7 . Table 1 presents the values of Cronbach's alpha for all the measures. The reliability test shows that two components in the questionnaire have a high internal consistency level with a psychometric score of 0.968 for SD and 0.939 for MR. Both measures have Cronbach's alpha values greater than 0.7. Therefore, it can be concluded that the measures have an acceptable level of reliability.

Table 1 - Cronbach's alpha of variables

\begin{tabular}{lcc}
\hline \multicolumn{1}{c}{ Measure } & $\begin{array}{c}\text { No of } \\
\text { items }\end{array}$ & $\begin{array}{c}\text { Cronbach's } \\
\text { alpha }\end{array}$ \\
\hline Supplier Development & 36 & \\
Manufacturing Responsiveness & $\underline{17}$ & $\underline{0.9689}$ \\
\hline
\end{tabular}

\subsection{Performance of Manufacturing Responsiveness}

A total of 17 performance indicators of MR that identified from the literature were used to assess the current MR performance. Fig. 1 shows the mean score values for all MR performance and the value is ranging from 3.27 to 3.80. Taking into consideration that the scale used in this study is $1-5$ with 3 as the middle point, the results show that the highest performance of manufacturing responsiveness is reacted to the changes in the industry (MR16) with mean score 3.80 , and closely followed by evaluating whether products development satisfy customer needs (MR15) with mean score 3.79. Meanwhile, the lowest performance is minimising material consumption (MR4) with a mean value of 3.27. 


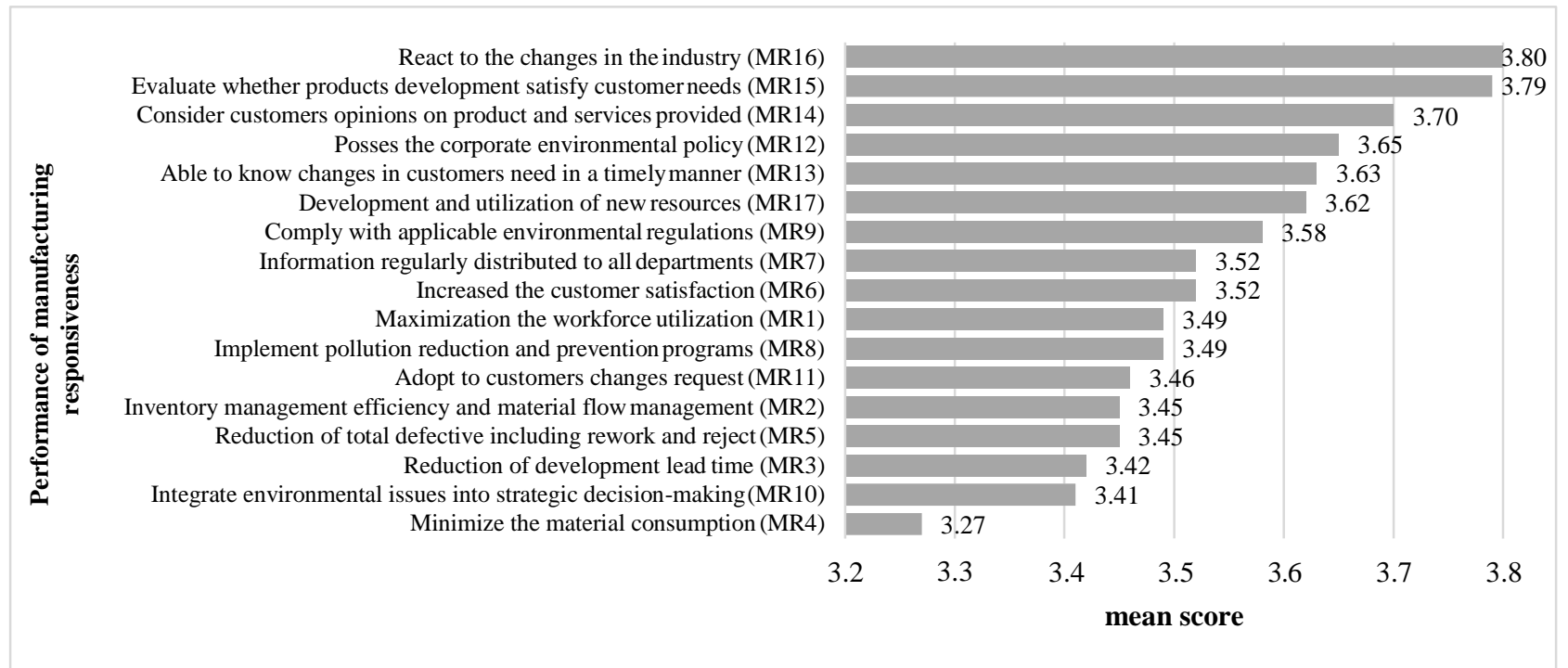

Fig. 1 - Mean score of manufacturing responsiveness performance

These results show that, on average, a manufacturing firm in Malaysia always associates the responsiveness with the ability to adapt and react to the changes in the industry. This is in line with the finding by Howleg [17] stated that excelling in the responsiveness dimensions; product, process, and volume is needed since misalignment between these dimensions will inevitably lead to a strategic conflict in the supply chain, and will influence an overall sub-optimal supply chain performance.

\subsection{Spearman Correlation Test}

Spearman correlation test was employed in order to investigate the relationship between SD practices and MR performance. A total of 612 matrices has been generated from this test. The results of this test show that all matrices generated were significant either at 0.01 or 0.05 where $166(27.12 \%)$ matrices were recorded having a moderate positive correlation relationship ranged from 0.401 to 0.589 as presented in Table 2 .

Table 2 - Spearman correlation of supplier development practices against manufacturing responsiveness performance

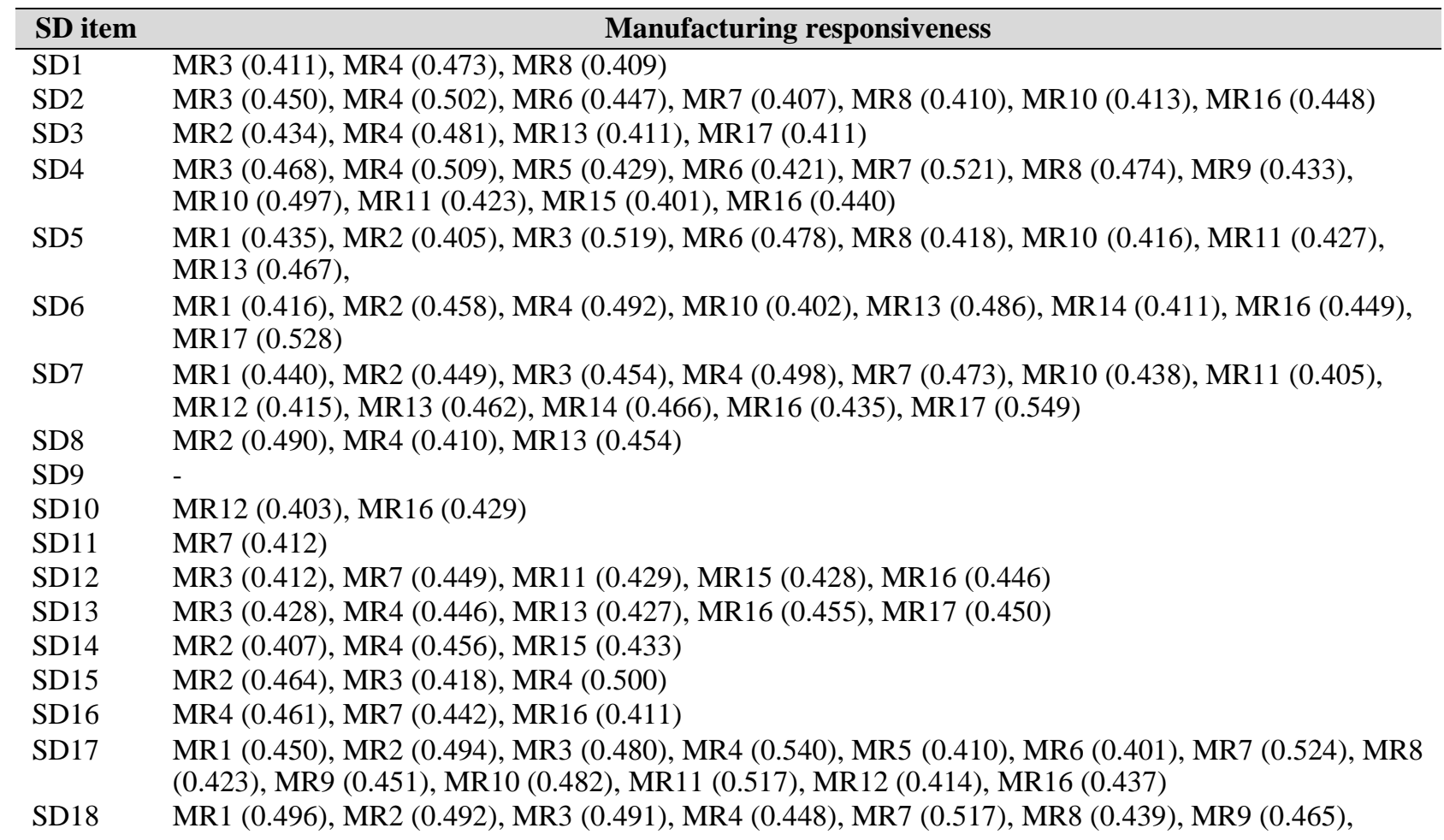




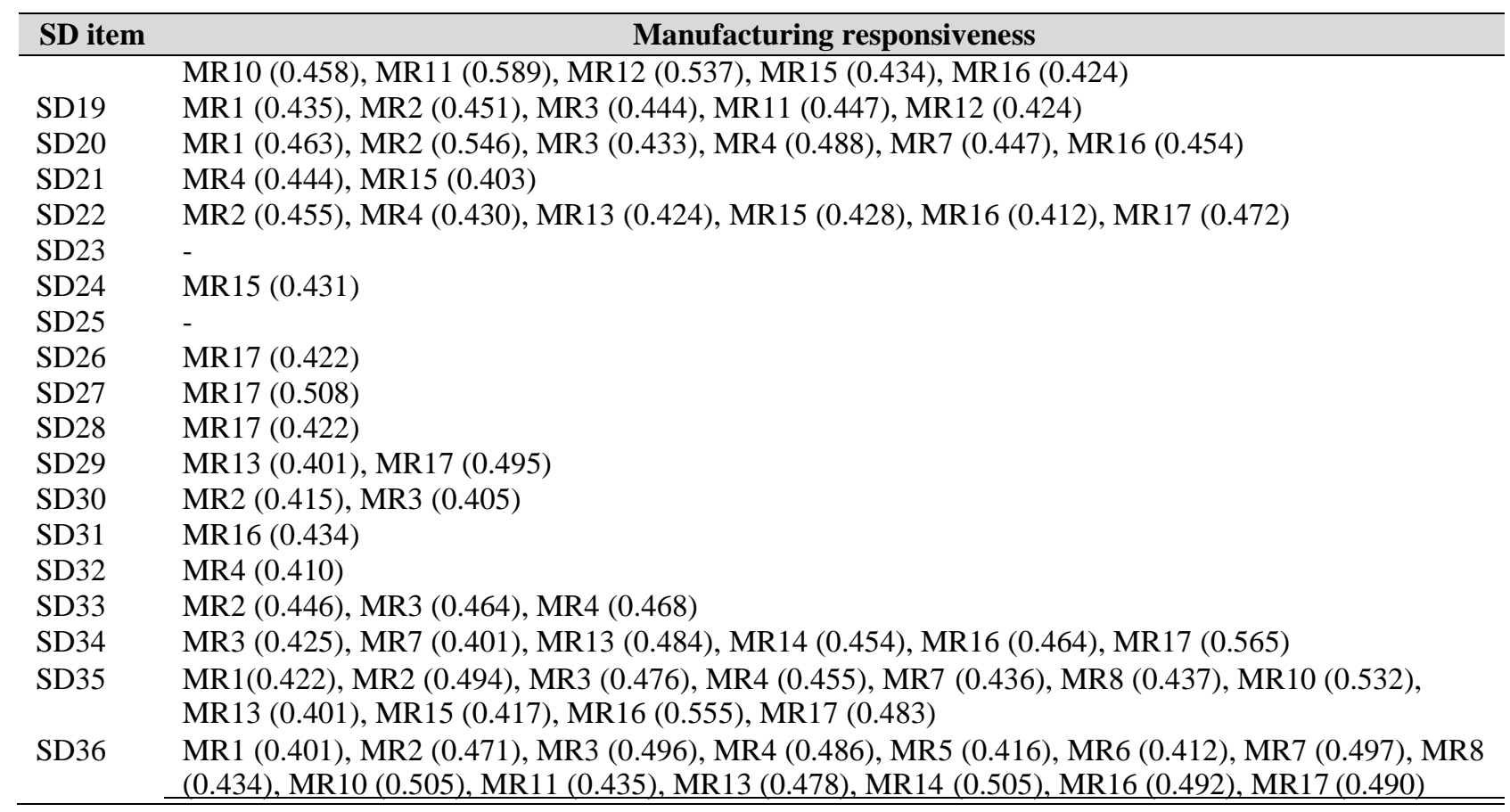

As recorded, the strongest correlation relationship appears between formal feedback of environmental assessment and evaluation (SD18) and adapt to customers' changes requests (MR11). This test results also suggest that manufacturing responsiveness is not strongly influenced by three SD initiatives; namely collaborate with the supplier to solve environmental problems (SD9), conduct an environmental audit (SD23) and establish supplier rating scheme to track performance (SD25). Even though the development of a supplier is likely to be one of the manufacturing strategies in helping enhancing manufacturing performance, it is important to understand that manufacturing strategy should be aligned with business strategy. Any misalignment can cause the full potential of the business outcome not fully achieved [18].

\section{Conclusion}

The key objective of this study is to examine the extent to which SD practices implemented by Malaysian manufacturers' will influence the manufacturing responsiveness. The results found suggest that the implementation of SD practices in Malaysia has a relatively optimistic, significant relationship with responsiveness performance in Malaysia. These results are particularly important as it is solely based in Malaysia and provide value specifically in strengthening the SD practices to further enhance a responsiveness level in manufacturing.

\section{Acknowledgement}

This research was co-funded by Universiti Teknikal Malaysia Melaka (UTeM) under the FRGS Grant (FRGS/2016/FTK-AMC/F00324), Ministry of Higher Education for MyBrain 15 programme, and Majlis Amanah Rakyat (MARA).

\section{Appendix}

\begin{tabular}{ll}
\hline Item & Supplier Development Practices \\
\hline SD1 & Conduct environmental awareness seminar \\
SD2 & Train suppliers in dealing with environmental issues \\
SD3 & Provide financial support to supplier \\
SD4 & Visit suppliers' premises \\
SD5 & Establish a total reduction cost team \\
SD6 & Provide expertise advise on technical and quality issue \\
SD7 & Establish the environmental teams \\
SD8 & Develop environmental expert employees transfer programme to supplier \\
SD9 & Collaborate with the supplier to solve environmental problems \\
SD10 & Joint efforts with the supplier to reduce waste \\
SD11 & Cooperate with suppliers on an environmental issue \\
SD12 & Joint effort on sustainability, cost and quality improvement
\end{tabular}




\begin{tabular}{ll}
\hline Item & Supplier Development Practices \\
\hline SD13 & Allow supplier involvement in green procurement and production \\
SD14 & Establish long-term contracts with suppliers \\
SD15 & Implement supplier environmental assessment program \\
SD16 & Possess formal process of supplier development \\
SD17 & Conduct formal environmental assessment and evaluation \\
SD18 & Formal feedback on environmental assessment and evaluation \\
SD19 & Informal/verbal feedback on environmental assessment and evaluation \\
SD20 & Perform environmental management of $2^{\text {nd }}$ tier supplier evaluation \\
SD21 & Certify the ISO14001 certification for supplier \\
SD22 & Conduct a social audit \\
SD23 & Conduct an environmental audit \\
SD24 & Establish supplier certification programs \\
SD25 & Establish supplier rating scheme to track performance \\
SD26 & Use questionnaire to collect information \\
SD27 & Supplier incentives and rewards for better environmental performance \\
SD28 & Establish environmental improvement target and performance goals \\
SD29 & Develop productivity improvement program \\
SD30 & Involvement of supplier in the early product design and development \\
SD31 & Work with a supplier in eco-design \\
SD32 & Provide related advice on eco-design in product development \\
SD33 & Collaborate with a supplier of green innovation and solutions \\
SD34 & Sharing information on an environmental topic \\
SD35 & Involvement of top management commitment in green supplier practices \\
SD36 & A formal long-term plan to improve supplier environmental performance \\
\hline
\end{tabular}

\section{References}

[1] Q. Zhang, M. A. Vonderembse, and J. S. Lim, "Manufacturing flexibility: Defining and analyzing relationships among competence, capability, and customer satisfaction," Journal of Operation Management, vol. 21, no. 2, pp. 173-191, 2003.

[2] S. M. Hatefi, S. M. Moshashaee, and I. Mahdavi, "A Bi-Objective Programming Model for Reliable Supply Chain Network Design under Facility Disruption," International Journal of Integrated Enineering., vol. 11, no. 6, pp. 80-92, 2019.

[3] A. Adam, Y. Yusof, M. Iliyas, Y. Saif, and N. Hatem, "Review on manufacturing for advancement of industrial revolution 4.0," International Journal of Integrated Enineering, vol. 10, no. 5, pp. 93-98, 2018.

[4] W. Li, P. K. Humphreys, A. C. L. Yeung, and T. C. E. Cheng, "The Impact of Specific Supplier Development Efforts on Buyer Competitive Advantage: An Empirical Model," International Journal of Production Economy, vol. 106, pp. 230-247, 2007.

[5] S. L. Avery, P. Swafford, and E. L. Prater, "Impact of supplier relationship management practices on buying firm performance : comparison of the United States and China," Operation Management Research, vol. 7, no. $1-2$, pp. 36-48, 2014.

[6] S. B. Modi and V. A. Mabert, "Supplier Development: Improving Supplier Performance through Knowledge Transfer," Journal of Operation Management, vol. 25, no. 2007, pp. 42-64, 2007.

[7] D. R. Krause, R. B. Handfield, and B. B. Tyler, "The Relationships between Supplier Development, Commitment, Social Capital Accumulation and Performance Improvement", Journal of Operation Management, vol. 25, no. 2, pp. 528-545, Mar. 2007.

[8] W. H. Wan Mahmood, R. Tukimin, M. R. Muhamad, and M. Z. Yusup, "Sustainable Criteria in a Supplier Selection: A Pre-review," Sci.int(Lahore), vol. 26, no. 5, pp. 1841-1844, 2014.

[9] C. Blome, D. Hollos, and A. Paulraj, "Green Procurement and Green Supplier Development: Antecedents and Effects On Supplier Performance,” International Journal of Production Research, vol. 52, no. 1, pp. 32-49, 2014.

[10] C. Bai and J. Sarkis, "Green Supplier Development: Analytical Evaluation Using Rough Set Theory,” Journal of Cleaner Production, vol. 18, no. 12, pp. 1200-1210, 2010.

[11] C. Sancha, A. Longoni, and C. Giménez, "Supplier development practices : Drivers and enablers in a global context," Journal of Purchasing \& Supply Management, vol. 21, no. 2, pp. 95-102, 2015.

[12] C. H. Ortega Jimenez, J. a. D. Machuca, P. Garrido-Vega, and R. Filippini, "The Pursuit of Responsiveness in Production Environments: From Flexibility to Reconfigurability," International Journal of Production Economics, vol. 163, pp. 157-172, May 2015.

[13] N. N. Gindy, S. M. Saad, and Y. Yue, "Manufacturing Responsiveness Through Integrated Process Planning 
and Scheduling," International Journal of Production Research, vol. 37, no. 11, pp. 2399-2418, Jul. 1999.

[14] Z. Ebrahim, N. A. Ahmad, and M. R. Muhamad, "Understanding Responsiveness in Manufacturing Operations," Sci.int(Lahore), vol. 26, no. 5, pp. 1663-1666, 2014.

[15] J. Uskonen and A. Tenhiälä, "The Price of Responsiveness: Cost Analysis of Change Orders in Make-to-Order Manufacturing," International Journal of Production Economics, vol. 135, no. 1, pp. 420-429, 2012.

[16] J. Váncza et al., "Cooperative and responsive manufacturing enterprises," CIRP Annals - Manufacturing Technology, vol. 60, no. 2, pp. 797-820, Jan. 2011.

[17] M. Holweg, "The three dimensions of responsiveness," International Journal of Operations \& Production Management, vol. 25, no. 7, pp. 603-622, Jul. 2005.

[18] P. Banchuen, I. Sadler, and H. Shee, "Supply chain collaboration aligns order-winning strategy with business outcomes," IIMB Management Review, vol. 29, no. 2, pp. 109-121, 2017. 